\title{
An easy and practical guide for imaging infection/inflammation by $\left[{ }^{18} \mathrm{~F}\right]$ FDG PET/CT
}

\author{
Alberto Signore $^{1,3}$ (1) Massimiliano Casali ${ }^{2} \cdot$ Chiara Lauri $^{1}$
}

Received: 22 April 2021 / Accepted: 19 May 2021 / Published online: 1 June 2021

(C) The Author(s) 2021

\begin{abstract}
Aim The aim of this mini-review was to summarize the role of positron emission tomography/computed tomography (PET/ $\mathrm{CT})$ with ${ }^{18}$ Fluorine-fluorodeoxyglucose $\left(\left[{ }^{18} \mathrm{~F}\right] \mathrm{FDG}\right)$ in inflammatory and infective processes, based on the published scientific evidence.

Methods We analysed clinical indications, patient preparation, image acquisition protocols, image interpretation, pitfalls and how to make the report of cardio-vascular diseases, musculoskeletal diseases and other inflammatory and infective systemic diseases.

Results of this analysis are shown in practical tables, easy to understand for daily routine consultation.

Conclusions Despite $\left[{ }^{18} \mathrm{~F}\right] \mathrm{FDG}$ is currently used in several inflammatory and infective diseases, standardized interpretation criteria are still needed in most cases. It is, therefore, foreseen the execution of multicentre clinical studies that, by adopting the same acquisition and interpretation criteria, may contribute to the standardization of this imaging modality.
\end{abstract}

Keywords $\left[{ }^{18} \mathrm{~F}\right] \mathrm{FDG} \mathrm{PET} / \mathrm{CT} \cdot$ Inflammation $\cdot$ Infection $\cdot$ Imaging $\cdot$ Interpretation criteria

\section{Introduction}

The diagnosis of an infection by means of imaging modalities mainly relies on the possibility to exclude aseptic inflammation due to degenerative process, or autoimmune/allergic reactions or simply irritative causes. Several radiological and Nuclear Medicine procedures are, therefore, involved,

Alberto Signore

alberto.signore@uniroma1.it

Massimiliano Casali

massimiliano.casali@ausl.re.it

Chiara Lauri

chiara.lauri@uniroma1.it

1 Nuclear Medicine Unit, Department of Medical-Surgical Sciences and of Translational Medicine, "Sapienza" University of Rome, 00161 Rome, Italy

2 Nuclear Medicine Unit, Oncology and High Technology Department, S. Maria Nuova Hospital, AUSL-IRCCS of Reggio Emilia, 42123 Reggio Emilia, Italy

3 Nuclear Medicine Unit, Department of Medical-Surgical Sciences and of Translational Medicine, Ospedale S. Andrea, Via di Grottarossa 1035, 00189 Rome, Italy in the search of which modality is more accurate in which clinical setting.

From the Nuclear Medicine point-of-view, this challenge to differentiate an infection from a sterile inflammation, has led to the production of hundreds of different radiopharmaceuticals that have open new ways to the possibility to specifically image the underlying process from a molecular point of view $[1,2]$.

Radiolabelled antibiotics [3, 4] or glucose derived sugars [5-8] have shown the potential to image bacteria, and, on the other hand, radiolabelled cytokines [9] or monoclonal antibodies [10] open the possibility to image different white blood cell subsets for histopathological characterization in vivo of the inflammatory/infective process.

Despite this enthusiastic output of new radiopharmaceuticals, the scintigraphy with radiolabelled white blood cells (WBCs), developed in early 1970 [11, 12], remains the Nuclear Medicine modality of choice for routine and accurate diagnosis of infection. Over the years, we learned that this technique strictly relies on the application of precise labelling modalities, image acquisition protocol and interpretation criteria that have been published as guidelines by the European Association of Nuclear Medicine (EANM) [13-18]. 
In the last two decades, given the increasing availability and application of positron emission tomography/computed tomography (PET/CT) with ${ }^{18}$ Fluorine-fluorodeoxyglucose $\left(\left[{ }^{18} \mathrm{~F}\right] \mathrm{FDG}\right)$ in several clinical contexts, infection and inflammation have also been extensively studied [19].

The great sensitivity of $\left[{ }^{18} \mathrm{~F}\right] \mathrm{FDG}$, together with the high quality of images provided by new generation tomographs, suggest the use of this modality for both diagnostic and follow-up purposes [19].

Nevertheless, well-standardized interpretation criteria, as it has been done for radiolabelled WBC scintigraphy, still do not exist for many infective or inflammatory disorders, thus resulting in different approaches adopted by each centre, and, most important, in a wide variability of reported accuracies of this modality that do not allow to make a direct comparison of different studies.

The need of well standardized protocols for acquisition and interpretation of $\left[{ }^{18} \mathrm{~F}\right] \mathrm{FDG}$ PET/CT images in this field, has become essential amongst the Nuclear Medicine community, as demonstrated by the increasing number of consensus documents and proposed interpretation criteria that have been published, for example, for imaging of prosthetic joint infections [20-24], diabetic foot osteomyelitis [25-27], cardiovascular inflammations and infections [18, 28-34], spondylodiscitis [35], inflammatory bowel diseases [36] and, more recently, for imaging with $\left[{ }^{18} \mathrm{~F}\right] \mathrm{FDG}$ by PET/ Magnetic Resonance Imaging (MRI) [37, 38].

Nonetheless, the proposed interpretation criteria for $\left[{ }^{18} \mathrm{~F}\right]$ FDG PET/CT imaging in many clinical indications still need to be universally validated.

\section{Purpose}

This mini-review aims at providing an overview on the state of art of $\left[{ }^{18} \mathrm{~F}\right]$ FDG PET/CT imaging in musculoskeletal infections, cardiovascular infections and inflammations, and systemic inflammatory and infective diseases with particular emphasis on image acquisition protocols and interpretation criteria.

\section{Methods}

In this mini-review, we summarize the available procedural recommendations for $\left[{ }^{18} \mathrm{~F}\right] \mathrm{FDG}$ PET/CT imaging in several infective and inflammatory conditions as derived from the literature of the past 20 years. An accurate and detailed analysis of the role of $\left[{ }^{18} \mathrm{~F}\right] \mathrm{FDG}$ PET/CT in each specific indication, resulting from an expert consensus, will be provided in the following article of this Special Issue of Clinical and Translational Imaging. In particular, an extensive literature research has been carried on the role of $\left[{ }^{18} \mathrm{~F}\right] \mathrm{FDG}$ PET/CT in osteomyelitis, prosthetic joint infections, spondylodiscitis, diabetic foot infections, infective endocarditis (both native an prosthetic valve endocarditis), cardiac implantable electronic devices infection, left ventricular assist deviceassociated infections, vascular graft infections, large vessel vasculitis, cardiac sarcoidosis, fever and inflammation of unknown origin, systemic sarcoidosis, inflammatory bowel disease, retroperitoneal fibrosis, fungal infections, tuberculosis and SARS CoV-2 infection.

In particular, each topic was summarized according to the following scheme:

- Clinical indications: gives an overview of the specific indications for the execution of $\left[{ }^{18} \mathrm{~F}\right] \mathrm{FDG}$ PET/CT in the diagnostic setting, for therapy evaluation or follow-up.

- Patient preparation: describes specific protocols, when required, that need to be adopted to increase the accuracy of this modality in detecting a specific disease.

- Imaging protocol: explains those specific acquisition protocols used for inflammatory and infective disease, when available.

- Interpretation criteria: provides a panoramic overview of recently published interpretation criteria of $\left[{ }^{18} \mathrm{~F}\right] \mathrm{FDG}$ PET/CT imaging in each specific disease.

- Possible pitfalls: this section summarizes the most frequently observed pitfalls and artefacts that need to be considered for a correct interpretation of the scan.

- Final report: describes how to report the exam (in addition to demographic data and technical information of the scan, type of tomograph, body weight and administered dose) with a focus on essential parts of the report. Time between injection and image acquisition should always be included in the report since it could be particularly useful for both long-term follow-up and therapy evaluation studies when $\mathrm{SUV}_{\text {max }}$ are compared.

\section{Results}

Results are summarized in easy to read tables, aiming at proving a useful tool in daily practice (Tables 1,2, 3, and 4).

It emerges that standardized protocols for patient preparation, image acquisition and interpretation criteria exist only for very limited clinical indications in the field of infection and inflammation and, in particular, for infective endocarditis, cardiac implantable devices infections, left ventricular assist device-associated infections, cardiac sarcoidosis, large vessel vasculitis and spondylodiscitis. For all other clinical indications, the recommendations for patient preparation and the acquisition protocols, commonly adopted for oncologic studies, are currently applied. As far as image interpretation is concerned, several criteria have been proposed for vascular graft infections, osteomyelitis, diabetic foot infections, 


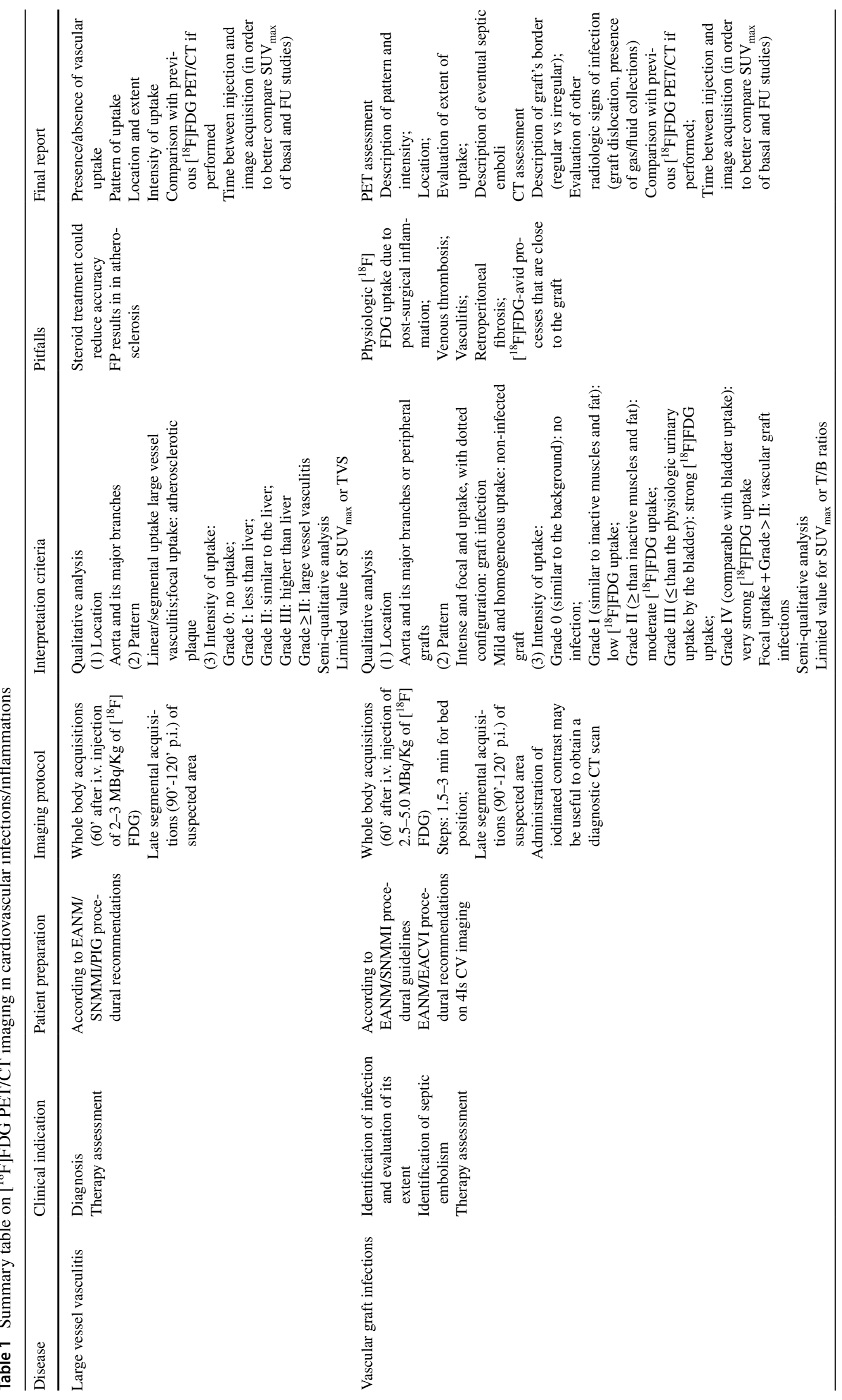




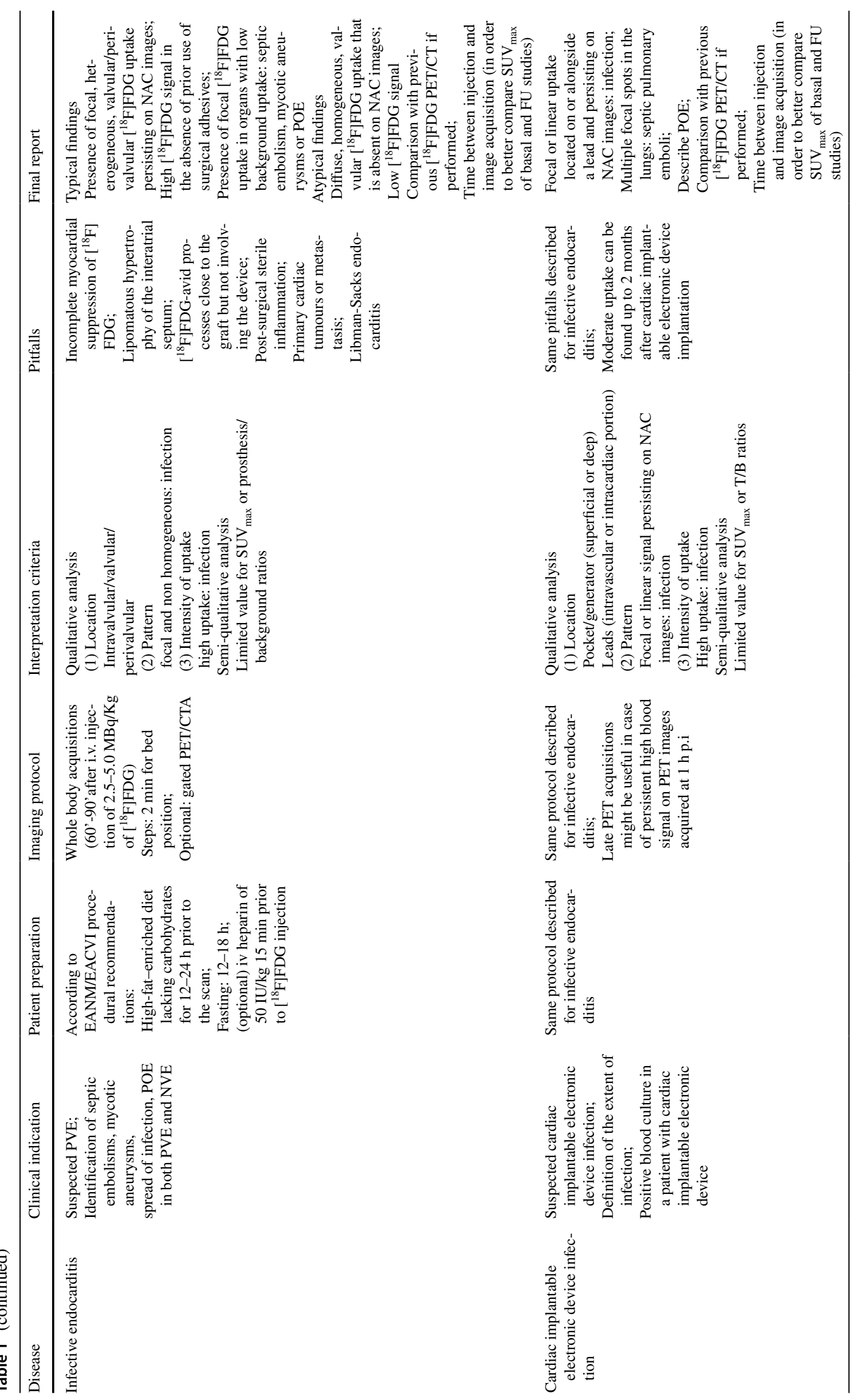




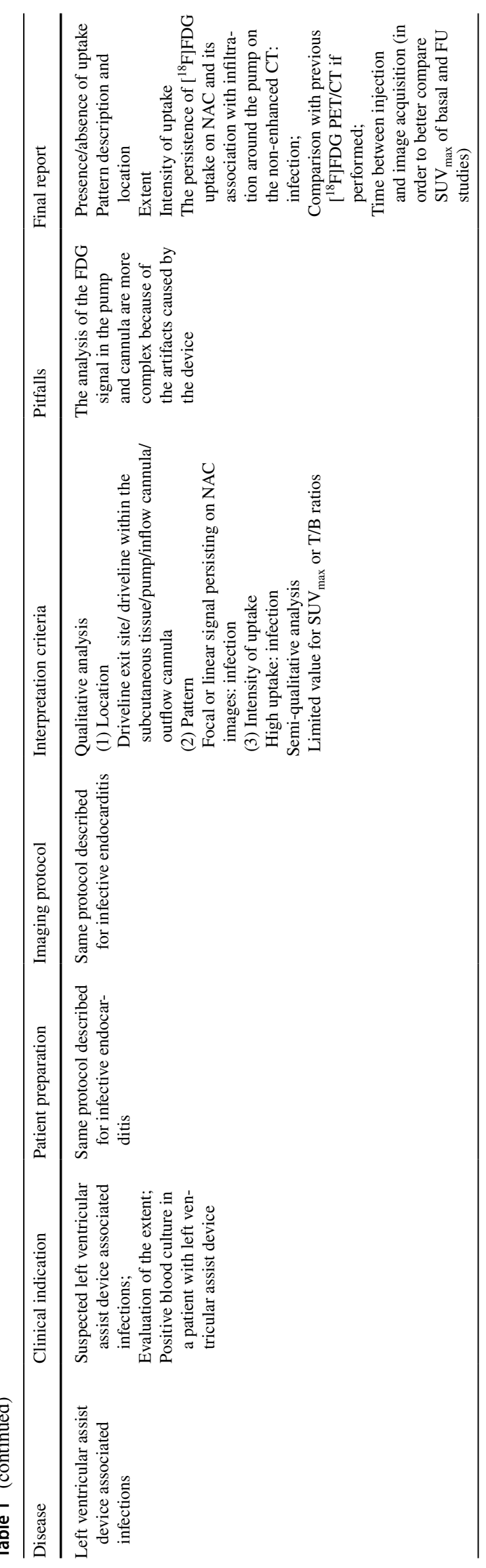



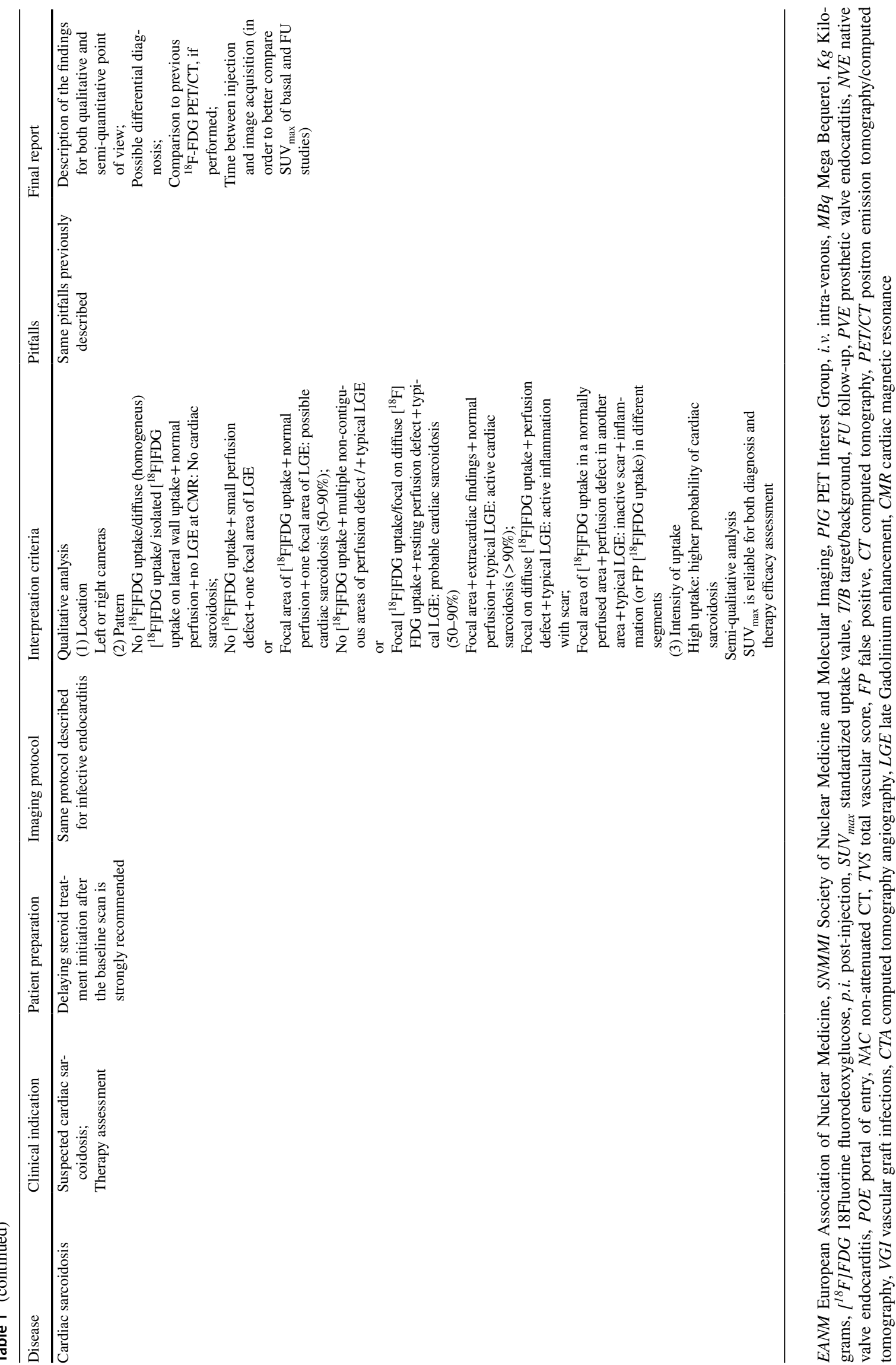


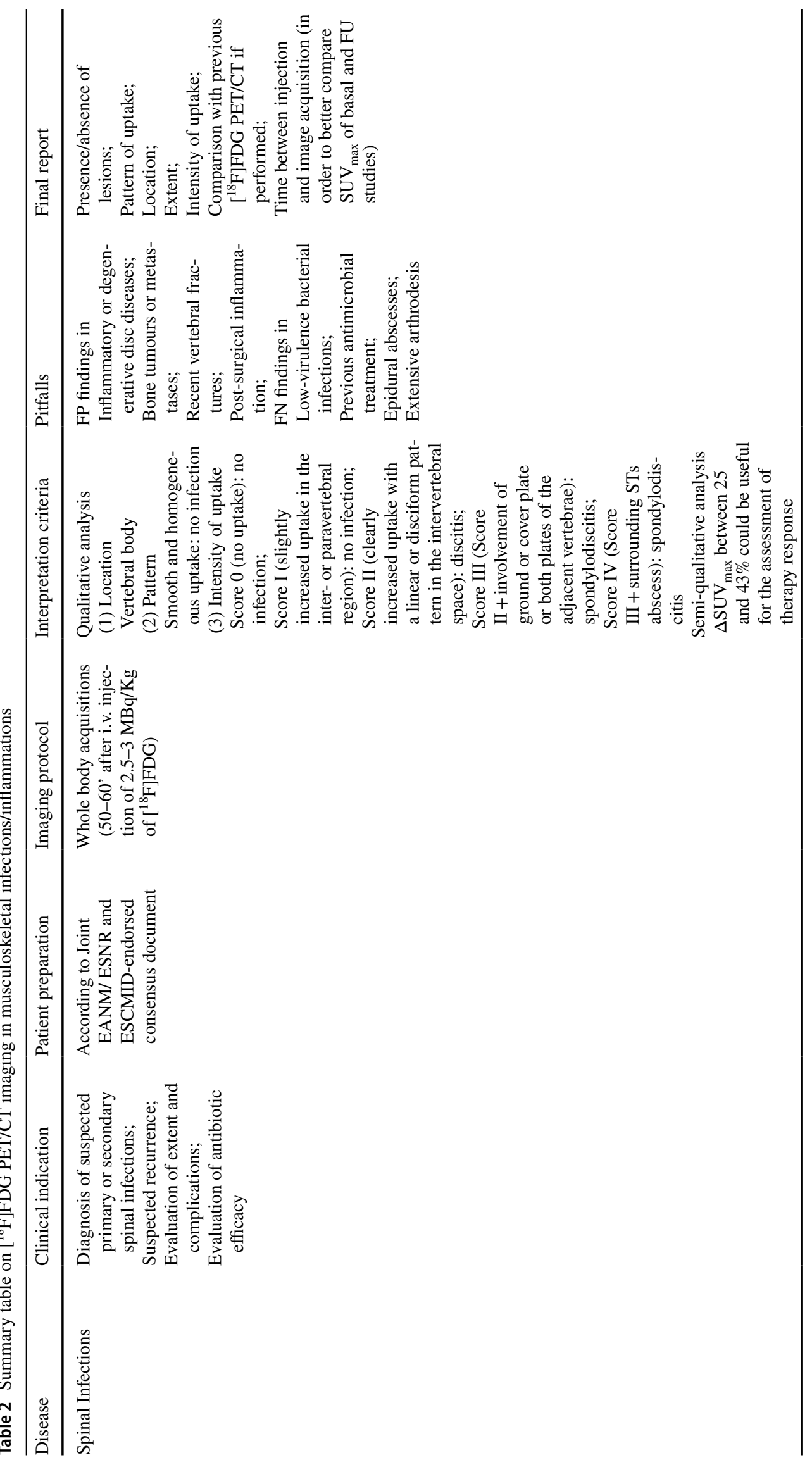




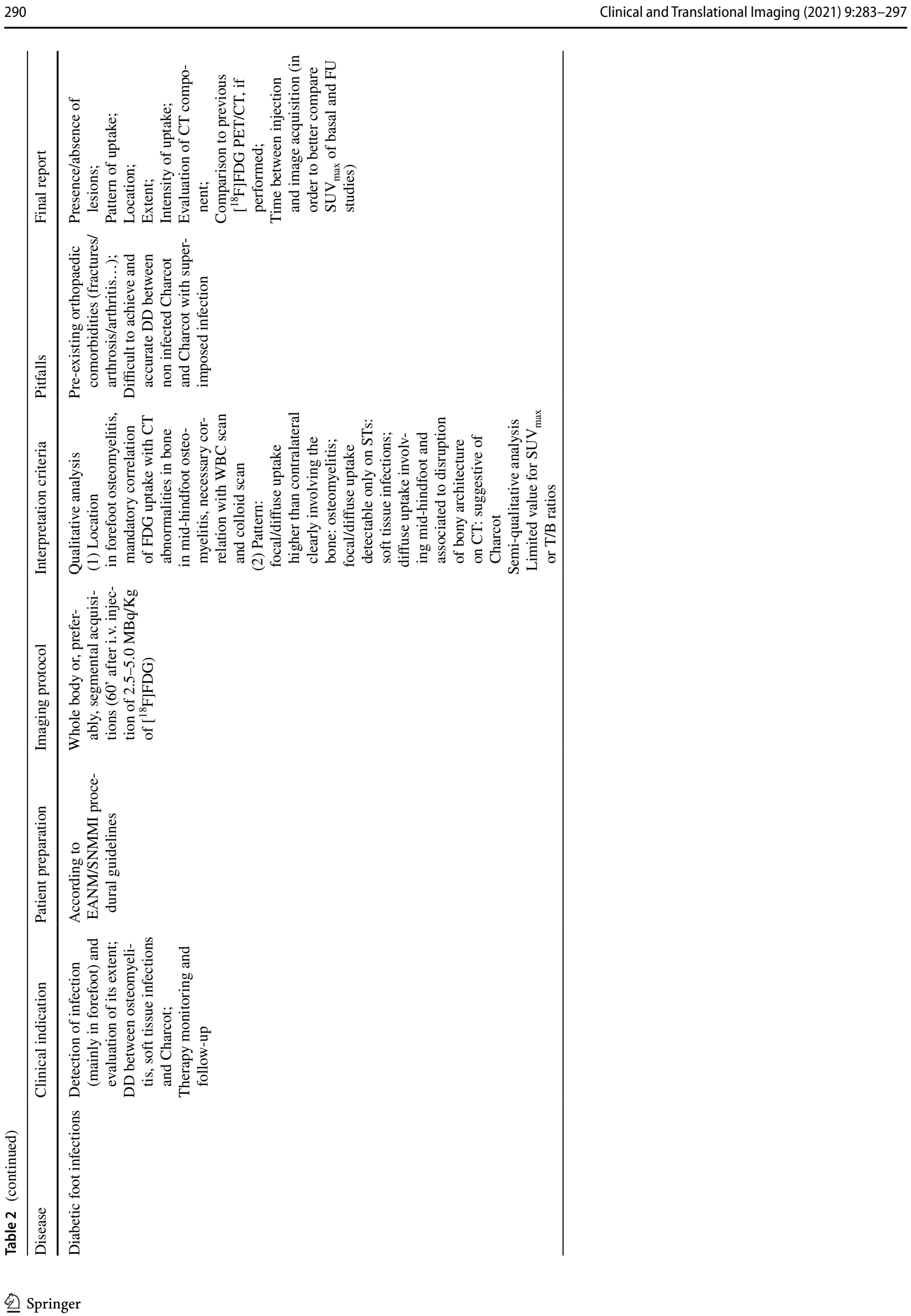




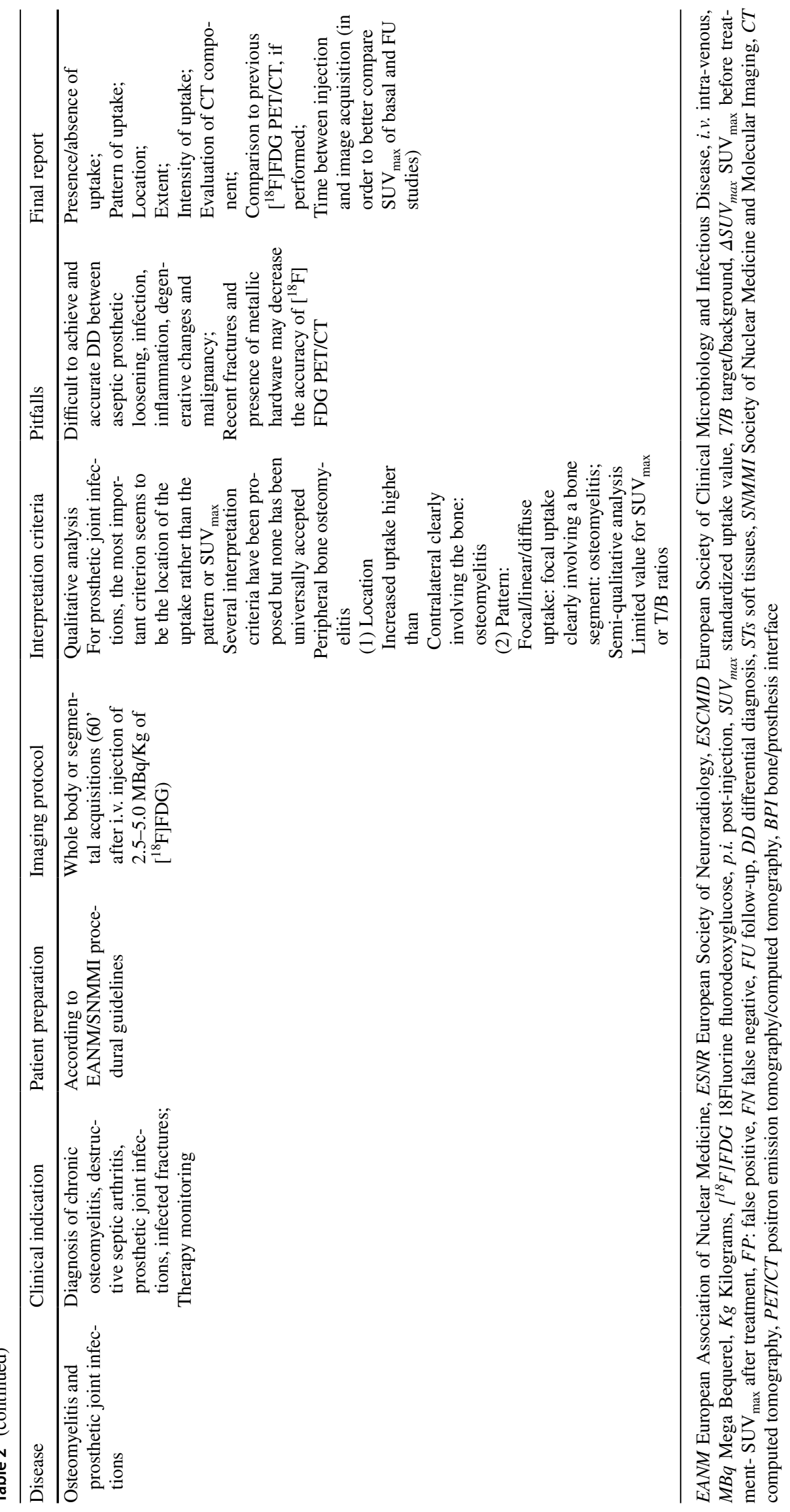




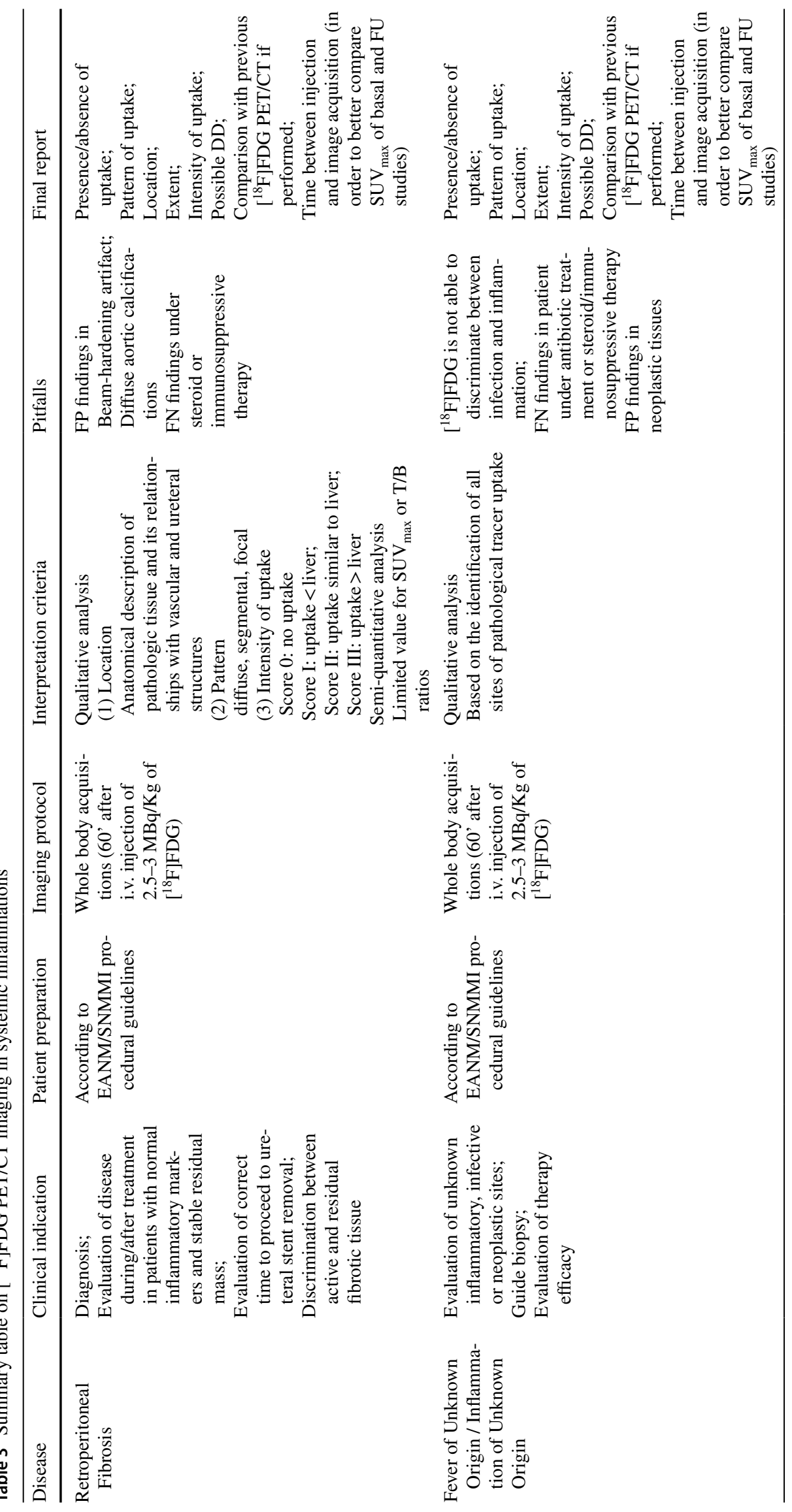




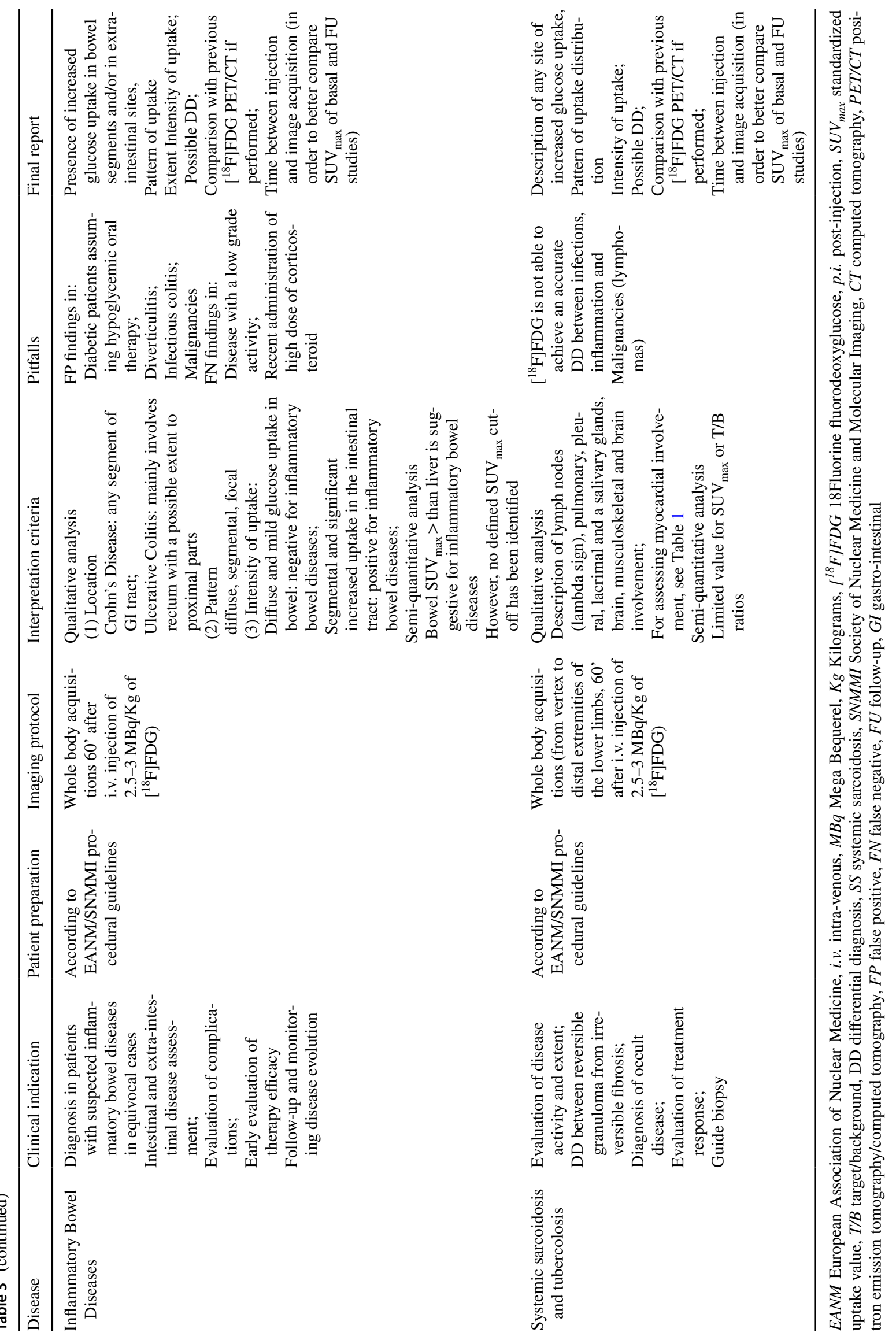




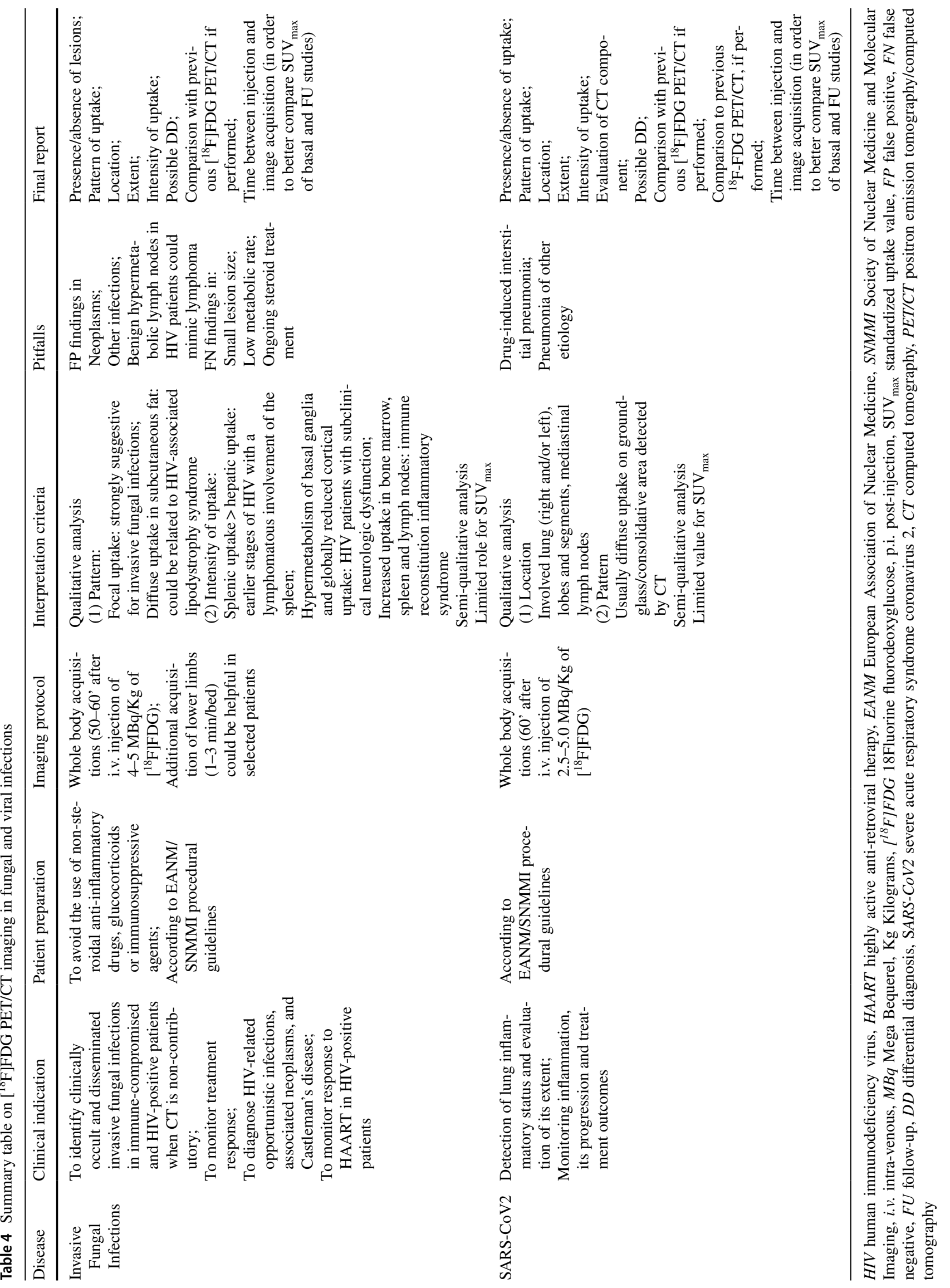


prosthetic joint infections, and systemic infections/inflammations, but they still need to be validated in larger multicentre studies being the reported diagnostic accuracy of single centre studies, extremely variable and generally lower than the diagnostic accuracy of WBC scintigraphy [20,27].

\section{Conclusions}

In summary, this article and the following, published in this journal, provide a useful tool for identifying several patterns of $\left[{ }^{18} \mathrm{~F}\right]$ FDG uptake able to discriminate between an infection and a sterile inflammation aiming at increasing the specificity and the accuracy of this radiopharmaceutical. This may have a great clinical impact on the management of each specific disease, may help to smooth the wide heterogeneity that is still evident in literature and will lay the basis for future comparative studies.

The definition of disease-specific acquisition protocols is warranted to increase the specificity and accuracy of this imaging modality. Moreover, it is mandatory, that the definition of precise and standardized interpretation criteria for $\left[{ }^{18} \mathrm{~F}\right] \mathrm{FDG}$ PET/CT imaging in different infective or inflammatory disorders need to be adopted and shared by several institutions and validated in large, possibly multicentre, studies.

\section{Teaching points}

- $\left[{ }^{18} \mathrm{~F}\right] \mathrm{FDG}$ has been proposed for the study of several inflammatory and infective diseases.

- Standardized acquisition and interpretation protocols exist for infective endocarditis and cardiac implantable electronic devices infections, cardiac sarcoidosis, large vessel vasculitis, as well as spondylodiscitis.

- Multicentre studies are needed to standardize the use of $\left[{ }^{18} \mathrm{~F}\right] \mathrm{FDG}$ in other inflammatory/infective diseases.

- Tables presented in this article can be used as a base for future studies.

Funding Open access funding provided by Università degli Studi di Roma La Sapienza within the CRUI-CARE Agreement. None.

\section{Declarations}

Conflicts of interest Alberto Signore, Chiara Lauri and Massimiliano Casali have nothing to declare.
Compliance with Ethics Guidelines This article does not contain any studies with human or animal subjects performed by any of the authors.

Open Access This article is licensed under a Creative Commons Attribution 4.0 International License, which permits use, sharing, adaptation, distribution and reproduction in any medium or format, as long as you give appropriate credit to the original author(s) and the source, provide a link to the Creative Commons licence, and indicate if changes were made. The images or other third party material in this article are included in the article's Creative Commons licence, unless indicated otherwise in a credit line to the material. If material is not included in the article's Creative Commons licence and your intended use is not permitted by statutory regulation or exceeds the permitted use, you will need to obtain permission directly from the copyright holder. To view a copy of this licence, visit http://creativecommons.org/licenses/by/4.0/.

\section{References}

1. Sollini M, Lauri C, Boni R, Lazzeri E, Erba PA, Signore A (2018) Current status of molecular imaging in infections. Curr Pharm Des 24(7):754-771

2. Signore A, Anzola KL, Auletta S, Varani M, Petitti A, Pacilio M, Galli F, Lauri C (2018) Current status of molecular imaging in inflammatory and autoimmune disorders. Curr Pharm Des 24(7):743-753

3. Auletta S, Galli F, Lauri C, Martinelli D, Santino I, Signore A (2016) Imaging bacteria with radiolabelled quinolones, cephalosporins and siderophores for imaging infection: a systematic review. Clin Transl Imaging 4:229-252

4. Auletta S, Varani M, Horvat R, Galli F, Signore A, Hess S (2019) PET radiopharmaceuticals for specific bacteria imaging: a systematic review. J Clin Med 8(2): 197

5. Li J, Zheng H, Fodah R, Warawa JM, Ng CK (2018) Validation of $2-18$ F-fluorodeoxysorbitol as a potential radiopharmaceutical for imaging bacterial infection in the lung. J Nucl Med 59(1):134-139

6. Zhu W, Yao S, Xing H, Zhang H, Tai YC, Zhang Y, Liu Y, Ma Y, Wu C, Wang H, Li Z, Wu Z, Zhu Z, Li F, Huo L (2016) Biodistribution and radiation dosimetry of the enterobacteriaceae-specific imaging probe [(18)F]fluorodeoxysorbitol determined by PET/CT in healthy human volunteers. Mol Imaging Biol 18(5):782-787

7. Yao S, Xing H, Zhu W, Wu Z, Zhang Y, Ma Y, Liu Y, Huo L, Zhu Z, Li Z, Li F (2016) Infection imaging with (18)F-FDS and first-in-human evaluation. Nucl Med Biol 43(3):206-214

8. Weinstein EA, Ordonez AA, DeMarco VP, Murawski AM, Pokkali S, MacDonald EM, Klunk M, Mease RC, Pomper MG, Jain SK (2014) Imaging Enterobacteriaceae infection in vivo with 18F-fluorodeoxysorbitol positron emission tomography. Sci Transl Med. 6(259):259ra146

9. Anzola LK, Galli F, Dierckx RA (2015) SPECT radiopharmaceuticals for imaging chronic inflammatory diseases in the last decade. Q J Nucl Med Mol Imaging 59(2):197-213

10. Lee HJ, Ehlerding EB, Cai W (2019) Antibody-based tracers for PET/SPECT imaging of chronic inflammatory diseases. ChemBioChem 20(4):422-436

11. Bagwe BA, Sharma SM (1976) Bone accumulation of 99mTclabeled leucocytes. J Nucl Med 17(4):313-316

12. McAfee JG, Thakur ML (1976) Survey of radioactive agents for in vitro labeling of phagocytic leukocytes. I Soluble agents J Nucl Med 17(6):480-487

13 de Vries EF, Roca M, Jamar F et al (2010) Guidelines for the labelling of leucocytes with 99mTc-HMPAO. Inflammation/ 
infection taskgroup of the European Association of Nuclear Medicine. Eur J Nucl Med Mol Imaging 37:842-848

14 Roca M, de Vries EF, Jamar F et al (2010) Guidelines for the labelling of leucocytes with 111In-oxine. Inflammation/infection taskgroup of the European Association of Nuclear Medicine. Eur J Nucl Med Mol Imaging 37:835-841

15. Signore A, Jamar F, Israel O et al (2018) Clinical indications, image acquisition and data interpretation for white blood cells and anti-granulocyte monoclonal antibody scintigraphy: an EANM procedural guideline. Eur J Nucl Med Mol Imaging 45:1816-1831

16. Glaudemans AWJM, Jutte PC, Cataldo MA et al (2019) Consensus document for the diagnosis of peripheral bone infection in adults: a joint paper by the EANM, EBJIS, and ESR (with ESCMID endorsement). Eur J Nucl Med Mol Imaging 46:957-970

17. Signore A, Sconfienza LM, Borens O et al (2019) Consensus document for the diagnosis of prosthetic joint infections: a joint paper by the EANM, EBJIS, and ESR (with ESCMID endorsement). Eur J Nucl Med Mol Imaging 46:971-988

18. Erba PA, Lancellotti P, Vilacosta I, Gaemperli O, Rouzet F, Hacker M, Signore A, Slart R, Habib G (2018) Recommendations on nuclear and multimodality imaging in ie and cied infections. Eur J Nucl Med Mol Imaging 45:1795-1815

19. Jamar F, Buscombe J, Chiti A et al (2013) EANM/SNMMI guideline for 18F-FDG use in inflammation and infection. $\mathrm{J}$ Nucl Med 54:647-658

20. Romanò CL, Petrosillo N, Argento G, Sconfienza LM, Treglia G, Alavi A, Glaudemans AWJM, Gheysens O, Maes A, Lauri C, Palestro CJ, Signore A (2020) The role of imaging techniques to define a peri-prosthetic hip and knee joint infection: multidisciplinary consensus statements. J Clin Med 9(8):2548

21. Reinartz P (2009) FDG-PET in patients with painful hip and knee arthroplasty: technical breakthrough or just more of the same. Q J Nucl Med Mol Imaging 53:41-50

22. Chacko TK, Zhuang H, Stevenson K, Moussavia B, Alavi A (2002) The importance of the location of fluorodeoxyglucose uptake in periprosthetic infection in painful hip prostheses. Nucl Med Commun 23:851-855. https://doi.org/10.1097/00006231200209000-00008

23. Love C, Marwin SE, Tomas MB, Krauss ES, Tronco GG, Bhargava KK, Nichols KJ, Palestro CJ (2004) Diagnosing infection in the failed joint replacement: a comparison of coincidence detection ${ }^{18} \mathrm{~F}$-FDG and ${ }^{111} \mathrm{In}$-labeled leukocyte $/{ }^{99 \mathrm{~m}} \mathrm{Tc}$-sulfur colloid marrow imaging. J Nucl Med 45:1864-1871

24. Stumpe KD, Nötzli HP, Zanetti M, Kamel EM, Hany TF, Görres GW, von Schulthess GK, Hodler J (2004) FDG PET for differentiation of infection and aseptic loosening in total hip replacements: comparison with conventional radiography and threephase bone scintigraphy. Radiology 231:333-341. https://doi. org/10.1148/radiol.2312021596

25. Familiari D, Glaudemans AW, Vitale V, Prosperi D, Bagni O, Lenza A, Cavallini M, Scopinaro F, Signore A (2011) Can sequential ${ }^{18} \mathrm{~F}$-FDG PET/CT replace WBC imaging in the diabetic foot? J Nucl Med 52:1012-1019. https://doi.org/10.2967/ jnumed.110.082222

26. Lauri C, Leone A, Cavallini M, Signore A, Giurato L, Uccioli L (2020) Diabetic foot infections: the diagnostic challenges. J Clin Med 9(6): 1779

27. Lauri C, Glaudemans AWJM, Campagna G, Keidar Z, Muchnik Kurash M, Georga S, Arsos G, Noriega-Álvarez E, Argento G, Kwee TC, Slart RHJA, Signore A (2020) Comparison of white blood cell scintigraphy, FDG PET/CT and MRI in suspected diabetic foot infection: results of a large retrospective multicenter study. J Clin Med 9(6):1645

28. Galea N, Bandera F, Lauri C, Autore C, Laghi A, Erba PA (2020) Multimodality imaging in the diagnostic work-up of endocarditis and cardiac implantable electronic device (CIED) infection. J Clin Med 9(7):2237

29. Lauri C, Iezzi R, Rossi M, Tinelli G, Sica S, Signore A, Posa A, Tanzilli A, Panzera C, Taurino M, Erba PA, Tshomba Y (2020) Imaging modalities for the diagnosis of vascular graft infections: a consensus paper amongst different specialists. J Clin Med 9(5):1510

30. Slart RHJA, Glaudemans AWJM, Gheysens O, Lubberink M, Kero T, Dweck MR, Habib G, Gaemperli O, Saraste A, Gimelli A, Georgoulias P, Verberne HJ, Bucerius J, Rischpler C, Hyafil F, Erba PA (2020) 4Is Cardiovascular Imaging: a joint initiative of the European Association of Cardiovascular Imaging (EACVI) and the European Association of Nuclear Medicine (EANM). Procedural recommendations of cardiac PET/CT imaging: standardization in inflammatory-, infective-, infiltrative-, and innervation- (4Is) related cardiovascular diseases: a joint collaboration of the EACVI and the EANM: summary. Eur Heart J Cardiovasc Imaging 21(12):1320-1330

31. Sah BR, Husmann L, Mayer D, Scherrer A, Rancic Z, Puippe G, Weber R, Hasse B, Cohort V (2015) Diagnostic performance of 18F-FDG-PET/CT in vascular graft infections. Eur J Vasc Endovasc Surg 49(4):455-464

32. Dorbala S, Ando Y, Bokhari S, Dispenzieri A, Falk RH, Ferrari VA, Fontana M, Gheysens O, Gillmore JD, Glaudemans AWJM, Hanna MA, Hazenberg BPC, Kristen AV, Kwong RY, Maurer MS, Merlini G, Miller EJ, Moon JC, Murthy VL, Quarta CC, Rapezzi C, Ruberg FL, Shah SJ, Slart RHJA, Verberne HJ, Bourque JM (2019) ASNC/AHA/ASE/EANM/HFSA/ISA/SCMR/SNMMI expert consensus recommendations for multimodality imaging in cardiac amyloidosis: part 1 of 2-evidence base and standardized methods of imaging. J Nucl Cardiol 26(6):2065-2123

33. Slart RHJA (2018) Writing group; Reviewer group; Members of EANM Cardiovascular; Members of EANM Infection \& Inflammation; Members of Committees, SNMMI Cardiovascular; Members of Council, PET Interest Group; Members of ASNC; EANM Committee Coordinator. FDG-PET/CT(A) imaging in large vessel vasculitis and polymyalgia rheumatica: joint procedural recommendation of the EANM, SNMMI, and the PET Interest Group (PIG), and endorsed by the ASNC. Eur J Nucl Med Mol Imaging 45(7):1250-1269

34. Soriano A, Pazzola G, Boiardi L, Casali M, Muratore F, Pipitone N, Catanoso M, Aldigeri R, Cimino L, Versari A, Salvarani C (2018) Distribution patterns of 18 F-fluorodeoxyglucose in large vessels of Takayasu's and giant cell arteritis using positron emission tomography. Clin Exp Rheumatol 36 Suppl 111(2):99-106

35. Lazzeri E, Bozzao A, Cataldo MA, Petrosillo N, Manfrè L, Trampuz A, Signore A, Muto M (2019) Joint EANM/ESNR and ESCMID-endorsed consensus document for the diagnosis of spine infection (spondylodiscitis) in adults. Eur J Nucl Med Mol Imaging 46(12):2464-2487

36. Panes J, Bouhnik Y, Reinisch W, Stoker J, Taylor SA, Baumgart DC, Danese S, Halligan S, Marincek B, Matos C, Peyrin-Biroulet L, Rimola J, Rogler G, van Assche G, Ardizzone S, Ba-Ssalamah A, Bali MA, Bellini D, Biancone L, Castiglione F, Ehehalt R, Grassi R, Kucharzik T, Maccioni F, Maconi G, Magro F, MartínComín J, Morana G, Pendsé D, Sebastian S, Signore A, Tolan D, Tielbeek JA, Weishaupt D, Wiarda B, Laghi A (2013) Imaging techniques for assessment of inflammatory bowel disease: joint ECCO and ESGAR evidence-based consensus guidelines. J Crohns Colitis 7(7):556-585

37. Catalano O, Maccioni F, Lauri C, Auletta S, Dierckx R, Signore A (2018) Hybrid imaging in Crohn's disease: from SPECT/CT 
to PET/MR and new image interpretation criteria. Q J Nucl Med Mol Imaging 62(1):40-55

38. Sollini M, Berchiolli R, Kirienko M, Rossi A, Glaudemans AWJM, Slart R, Erba PA (2018) PET/MRI in Infection and Inflammation. Semin Nucl Med 48(3):225-241
Publisher's Note Springer Nature remains neutral with regard to jurisdictional claims in published maps and institutional affiliations. 